\begin{tabular}{|c|l|}
\hline Title & Mesoscale Modeling of Chloride Penetration in Unsaturated Concrete Damaged by Freeze Thaw Cycling \\
\hline Author(s) & Wang, Licheng; Ueda, Tamon \\
\hline Citation & $\begin{array}{l}\text { Journal of Materials in Civil Engineering, 26(5), 955-965 } \\
\text { https://doi.org/10.1061/A SCE)MT.1943-5533.0000901 }\end{array}$ \\
\hline Issue Date & 201405-01 \\
\hline Doc URL & http://hdl.handle.net/2115/56842 \\
\hline Type & article (author version) \\
\hline File Information & JMCE26-5955-965.pdf \\
\hline
\end{tabular}

Instructions for use 


\title{
Mesoscale Modeling of Chloride Penetration in Unsaturated Concrete Damaged by Freeze-Thaw Cycling
}

\author{
Licheng $\mathrm{WANG}^{1}$ and Tamon $\mathrm{Ueda}^{2}$
}

Abstract: For concrete structures exposed to frost attack, cracks or microcracks induced by freeze-thaw cycling can format interconnecting flow paths and allow more water or chloride ions to penetrate into the bulk concrete. It will subsequently facilitate further deterioration of concrete structures and accelerate the corrosion of embedded reinforced steel bars. Moreover, in reality most concrete structures are rarely fully saturated, so that chloride transportation in unsaturated concrete must be studied with respect to the water moving process in order to cover the real existing service conditions. In the current work, a numerical simulation method based on the mesoscale composite structure of concrete, named the lattice network model, is established to analyze the penetration property of concrete; especially the effects of microcracking induced by freeze-thaw damage on the unsaturated flow behavior are investigated. In the mesoscale model, concrete is treated as a three-phase composite material consisting of coarse aggregates, mortar matrix and interfacial transition zone (ITZ) between the aggregate and the mortar matrix. The diffusivities of each phase, i.e., water and chloride diffusion coefficients, is separately characterized and quantified in terms of the published test results. The unsaturated flow theory for capillary water absorption and chloride transport is employed to simulate the ingress of water and chloride ions into concrete. It is found

${ }^{1}$ Associate Professor, State Key Laboratory of Coastal and Offshore Engineering, Dalian Univ. of Technology, No. 2, Linggong Road, Dalian 116024, China. E-mail: wanglicheng2000@163.com

${ }^{2}$ Professor, Division of Engineering and Policy for Sustainable Environment, Faculty of Engineering, Hokkaido Univ., Kita-ku, Kita 13, Nishi 8, Sapporo 060-8628, Japan. 
that the water absorption and chloride penetration are substantially influenced by the frost action, and the cumulative absorbed water and chloride penetration depth are increased with the increase of freezing-thawing cycles (FTCs). Furthermore, the numerical predictions about water absorption and chloride profiles are compared with the experimental measurements. The comparisons indicate that numerical predictions agree very well with the test data.

CE Database subject headings: Concrete; Cracking; Freeze-thaw; Chlorides; Absorption

Author keywords: Chloride; unsaturated concrete; freezing-thawing cycles (FTCs); numerical modeling; mesoscale; lattice network model.

\section{Introduction}

Degradation of concrete structures has attracted more and more attention in recent years although concrete was once treated as a durable maintenance-free construction material. The deterioration mechanism of concrete facilities can be summarized as carbonation, sulfate and chloride attack, freezing-thawing cycles (FTCs), and so on. Generally, in the ingressive environment, penetration of chloride ions through concrete cover is a major factor affecting the durability of reinforced concrete structures because it can result in corrosion of the reinforcing bars (Boddy et al. 1999). Furthermore, the formation of rust in the interface between steel bars and surrounding concrete is associated with large volume expansion, which may cause cracking, spalling, and delamination of the concrete cover. Particularly in the severe rust cases, the bearing capacity of the structural members may be decreased due to the reduction of the cross-section of reinforcement (Ababneh et al. 2003). Therefore, there is growing interest in clarifying the deterioration mechanism and to predict the life-cycle performance of concrete structures. In reality, most concrete structures are always subjected to cyclic drying-wetting actions by wind, sun, rain/snow fall and water level of ocean/river. Coastal and marine structures in splash and 
tidal zones are a good example. Concrete within the splashing and tidal zones is not fully saturated.

The process of chloride ingress in partially saturated concrete is clearly different from that in fully saturated concrete because of the different driving force and transport mechanism (Nagesh and Bhattacharjee 1998). There exist two transport mechanisms for chloride ions penetrating in the unsaturated concrete; one is the capillary suction of chloride-containing water into partially water-filled pores and the other is the diffusion of chloride ions in water-filled pores. It has been shown that the transport of chlorides by capillary suction makes greater contribution than by diffusion in the partially saturated concrete (Lunk 1998; Nagesh and Bhattacharjee 1998), since under this condition the diffusion is a quite slow process in comparison with the capillary suction. This has already been confirmed by some experimental findings. For example, Nielsen and Geiker (2003) concluded that chloride diffusion coefficient in saturated condition was about 5 times higher than that with RH of $65 \%$. Climent et al. (2002) and de Vera et al. (2007) found that the diffusion coefficient decreased about two orders of magnitude, from $6 \times 10^{-12} \mathrm{~m}^{2} / \mathrm{s}$ to $2 \times 10^{-14} \mathrm{~m}^{2} / \mathrm{s}$ approximately, when the degree of water saturation was lowered from values of $0.7-0.8$ to values of 0.3-0.4. The fact that corrosion of steel reinforcement in the splashing and tidal zone is most severe can be partly attributed to the alternate wetting and drying which result in high chloride and oxygen content. To properly describe the deterioration process of reinforced concrete structure under the unsaturated condition, the chloride ingress by capillary absorption must be taken into account.

In addition, water penetration depth significantly depends on the characteristics of porosity in the surface layer of concrete, including the pore diameter and distribution, and the pore continuity and tortuosity (McCarter et al. 1992; Kelham 1988). When subjected to freeze-thaw cycling, concrete deteriorates through a variety of physical and chemical process, which will result in cracking, and subsequently increase the porosity of concrete. It has been widely realized that the 
existence of cracks in concrete can significantly modify the transport properties of the material (Gérard et al. 1996; Wang et al. 1997; Aldea et al. 1999; Yang et al. 2006; Sahmaran et al. 2007). Moreover, cracking due to freeze-thaw cycling generally forms interconnecting flow paths and allows more water or chloride ions to penetrate into the concrete, thus facilitating further deterioration. A number of studies have shown that increased chloride transport due to cracking can accelerate the corrosion of reinforced steel in concrete (Schiessl and Raupach1997; Qi 2003; Jaffer and Hansson 2008). Therefore, in a cold and ingressive environment, it is necessary to properly take into account the internal cracking or damage of concrete caused by freeze-thaw cycling in order to realistically estimate the reduction of bearing capacity of RC structural members and then to predict their durability and life-cycle performance. The mechanical behavior of frost-damaged concrete has been successfully simulated by means of a mesoscale numerical model (Ueda et al. 2009). However, few works have been done to investigate the agents moving process and mechanism in FTC-damaged concrete, especially under the unsaturated condition.

In the present paper a lattice network model in mesoscale is proposed which is able to simulate the chloride transport process in unsaturated concrete and account for the damage induced by freeze-thaw cycling. The formulation of the model and its implementation into a three-phase composite structure of concrete is presented on the basis of reasonable quantification of transport characteristics of water and chlorides into mortar, interfacial transition zone (ITZ) and cracks. The application of the model is illustrated on a numerical example in which the concrete is subjected to different FTCs in order to investigate the influence of damage or cracking on the chloride penetration. The result of numerical analysis is compared with the previous test data published in literature. 


\section{Chloride binding capacity}

Under a natural and open condition, if the gravity or water pressure gradient is ignored, the principal penetration processes for chlorides in concrete can be represented by diffusion (which is caused by the concentration gradient of dissolved ions) and the convection as a result of bulk moving water (which is induced by the capillary absorption). In addition, when chlorides penetrate into concrete, it has been observed that some of the chlorides are chemically and physically bound to the hydrated products of cement or the surfaces of some gel pores within concrete. This behavior is called chloride binding capacity of concrete. Therefore, chloride in concrete is commonly categorized as free and bound chloride. The total chloride concentration, $C_{t}$, can then be expressed as

$$
C_{t}=C_{f}+C_{b}
$$

in which $C_{f}$ is the free chloride concentration in $\mathrm{kg} / \mathrm{m}^{3}$ of the solution; $C_{b}$ is the bound chloride concentration. The chloride binding capacity is usually defined as the ratio of the change in the free chloride concentration to the change in the total chloride concentration, which can be written as follows:

$$
\frac{\partial C_{f}}{\partial C_{t}}=\frac{1}{\frac{\partial C_{t}}{\partial C_{f}}}=\frac{1}{\frac{\partial\left(C_{f}+C_{b}\right)}{\partial C_{f}}}=\frac{1}{1+\frac{\partial C_{b}}{\partial C_{f}}}
$$

Here $\lambda=\frac{\partial C_{b}}{\partial C_{f}}$ is an experimentally obtained parameter. It is apparent that in concrete only the free chloride is responsible for the steel corrosion because the bound chloride cannot migrate freely through the concrete cover to reach the surface of embedded steel bars. Thereafter, in the current study, the governing equation for chloride ingress, including diffusion and convection, is formulated in terms of the free chloride concentration. Additionally, the chlorides brought by the concrete 
mixtures are not considered here.

\section{Water convection induced by capillary absorption}

112 When a dried (or unsaturated) concrete is in contact with water, convection of bulk moving water induced by capillary absorption serves as the main carrier for chloride ingress. Generally, the water movement is not influenced by the existence of chloride ions. The flux of mass of chloride at any point in concrete, $J_{c}$, in $\mathrm{kg} / \mathrm{m}^{2} . \mathrm{s}$, due to capillary absorption can be written as (Nagesh and Bhattacharjee 1998):

$$
J_{c}=-C_{f} D_{w}(\theta) \frac{d \theta}{d x}
$$

where $D_{w}(\theta)$ is the water or solution diffusivity in $\mathrm{m}^{2} / \mathrm{sec}$ if the chloride ions are supposed to have the same transport speed with water; $\theta$, here and elsewhere in the text, is the normalized water content, scaled to be zero and one for the initial (dried state) and saturated volumetric solution contents (i.e., volume of solution/bulk volume of concrete in $\mathrm{m}^{3}$ of solution $/ \mathrm{m}^{3}$ of concrete), $\Theta_{i}$ and $\Theta_{s}$, respectively; $x$ is the space coordinate in concrete perpendicular to the exposed surface. Obviously, $\theta$ can be written as:

$$
\theta=\frac{\Theta-\Theta_{i}}{\Theta_{s}-\Theta_{i}}
$$

in which $\Theta$ is the volumetric solution content in $\mathrm{m}^{3}$ of solution $/ \mathrm{m}^{3}$ of concrete. In experiments, the initial state $\Theta_{i}$ is specially reached by drying a specimen to constant weight at $105^{\circ} \mathrm{C}$ (in some experiments, lower than $105^{\circ} \mathrm{C}$ ), so that, in this case $\Theta_{i}$ is close or equal to zero. The saturated state is reached by direct contact with an unlimited supply of water, which is approximately equal to the volume fraction porosity (Hall 1989). Apparently, the porosity of a material is an important parameter to influence the total water volume when exposed to the water source. Additionally, in the current study, the difference of diffusivity between salt solution and pure water is neglected 
implying that $D_{w}(\theta)$ is independent of the solute concentration.

As has been pointed out, in absorption tests on capillary suction of $\mathrm{NaCl}$ solution, the speed of the chloride ions ingress is lower than the speed of water due to the filter effect of the cement paste, which is also called the retardation effect. This effect can be characterized by a retardation coefficient $R$, defined as (Lunk 1998):

$$
R=1-\frac{x_{\mathrm{cl}}}{x_{w}}
$$

where $x_{\mathrm{cl}}$ is the mean chloride penetration depth and $x_{w}$ is the mean water penetration depth.

In order to consider this effect, the flux of mass of chloride ions in Eq. (3) will be reduced by multiplying the water diffusivity with the coefficient (1-R) (Roelfstra et al. 2004).

\section{Chloride diffusion under unsaturated state}

Because of the retardation effect of cement paste, the free chloride concentration is likely to vary along the penetrating direction, even in the water-filled pores, so that a concentration gradient will be generated. This concentration gradient, therefore, causes diffusion of chloride ions from higher concentration to lower concentration. Usually the diffusion of chloride ions is formulated with Fick's second law:

$$
J_{d}=-D_{\mathrm{cl}}(\theta) \frac{d C_{f}}{d x}
$$

where $J_{d}$ is the flux of mass of chloride induced by the diffusion process; $D_{\mathrm{cl}}(\theta)$ is the chloride diffusion coefficient in $\mathrm{m}^{2} / \mathrm{sec}$ and is dependent on the water content.

The chloride diffusion in concrete is a humid process, which can occur only if water is present in the pores of concrete (Saetta et al. 1993). Therefore, it has been stated that water content (sometime referred as relative humidity) in concrete plays an important role in the chloride 
diffusion process. Generally speaking, the diffusion coefficient of chloride decreases with the decrease of water content. Two different models to describe the interrelation between chloride diffusion coefficient and water content (or relatively humidity) are available currently.

The first model was developed by Saetta et al. (1993), using an $S$-shaped curve to account for the effect of relative humidity, $\mathrm{RH}$, on the chloride diffusion coefficient, which can be expressed as:

$$
\frac{D_{\mathrm{cl}}(\mathrm{RH})}{D_{\mathrm{cl} 1}}=\left(1+\frac{(1-\mathrm{RH})^{4}}{\left(1-\mathrm{RH}_{\mathrm{c}}\right)^{4}}\right)^{-1}
$$

where $D_{\mathrm{cl}}(\mathrm{RH}), D_{\mathrm{cl} 1}$ are the chloride diffusion coefficient at any relative humidity and at the saturated state, respectively; $\mathrm{RH}_{\mathrm{c}}$ is the critical relative humidity, at which $D_{\mathrm{cl}}\left(\mathrm{RH}_{\mathrm{c}}\right)=0.5 D_{\mathrm{cll}}$, and given as $75 \%$ by Saetta et al. (1993). When $\mathrm{RH}$ drops below $\mathrm{RH}_{\mathrm{c}}$, the ion diffusivity shows a rough drop due to the loss of liquid connectivity inside the porous network. In terms of Eq. (7), Nielsen and Geiker (2003) experimentally determined $\mathrm{RH}_{\mathrm{c}}$ to be $83 \%$ for a Portland cement mortar with $w / c=0.5$. De Vera et al. (2007) found that, for concrete with $w / c=0.6, \mathrm{RH}_{\mathrm{c}}$ is fitted as $83.1 \%$. In the current study, the curves of Eq. (7) with the previously proposed values of $\mathrm{RH}_{\mathrm{c}}$ are presented in Fig. 2. To use Eq. (7), the relative humidity RH in Eq. (7) can be transferred into the normalized water content $(\theta)$ with the method proposed by Akita et al. (1994) as follows:

$$
\theta=a_{1}+a_{2} \mathrm{RH}+a_{3} \alpha+a_{4} \mathrm{RH}^{2}+a_{5} \mathrm{RH} \alpha+a_{6} \alpha^{2}+a_{7} \mathrm{RH}^{3}+a_{8} \mathrm{RH}^{2} \alpha+a_{9} \mathrm{RH} \alpha^{2}+a_{10} \alpha^{3}
$$

in which $a_{1} \sim a_{10}$ are constants, and their values have been experimentally fitted as $33.4,1.46,-0.287$, $-1.58 \times 10^{-2},-1.45 \times 10^{-2}, 4.22 \times 10^{-4}, 7.73 \times 10^{-5}, 1.74 \times 10^{-4},-4.22 \times 10^{-6}$ and 0 , respectively; $\alpha$ is the water/cement ratio expressed in percentage (e.g. for $w / c=0.5$, the value of $\alpha$ is 50 ). The validity of Eq. (8) is illustrated in Fig. 1 by comparing the predicted results with available test data. It is evident that the method proposed by Akita et al. (1994) (Eq. (8)) is able to build an approximate relation between the $\mathrm{RH}$ and $\theta$ if ignoring the scatter of test results.

Saeki and Niki (1996) suggested another model with an empirical relationship to consider the 
influence of water content on chloride diffusion coefficient:

$$
\frac{D_{\mathrm{cl}}(\theta)}{D_{\mathrm{cl} 1}}=0.0032 \times 10^{0.025 \theta}
$$

$D_{\mathrm{cl}}(\theta)$ in Eq. (9) has the same definition as $D_{\mathrm{cl}}(\mathrm{RH})$ in Eq. (7) considering the relationship between relative humidity RH and relative water content $\theta$. The comparison of the above two models, as well as compared with available test data, is depicted in Fig. 2. It can be seen that the curve obtained from Eq. (7) with $\mathrm{RH}_{\mathrm{c}}=83 \%$ matches better with the experimental data than the curve from Eq. (9). Thereafter, Eq. (7) with $\mathrm{RH}_{\mathrm{c}}=83 \%$ will be adopted in the subsequent analysis.

\section{Combined formulation of convection and diffusion}

Therefore, the total flux of chloride mass can be written as:

$$
J=J_{c}+J_{d}=-\left[C_{f} D_{w}(\theta)(1-R) \frac{\partial \theta}{\partial x}+D_{\mathrm{cl}}(\theta) \frac{\partial C_{f}}{\partial x}\right]
$$

Considering the mass balance of chloride ions in an infinitesimal volume of concrete, the following equation can be obtained:

$$
\frac{\partial C_{t}}{\partial t}=-\frac{\partial J}{\partial x}
$$

By substituting Eq. (10) into Eq. (11) and applying Eq. (2), the governing equation for chloride ingress in a 1-D case can thus be expressed as

$$
\frac{\partial C_{t}}{\partial t}=\frac{\partial C_{t}}{\partial C_{f}} \frac{\partial C_{f}}{\partial t}=(1+\lambda) \frac{\partial C_{f}}{\partial t}=\frac{\partial}{\partial x}\left[C_{f} D_{w}(\theta)(1-R) \frac{\partial \theta}{\partial x}+D_{\mathrm{cl}}(\theta) \frac{\partial C_{f}}{\partial x}\right]
$$

Rearranging Eq. (12), one can obtain

$$
\frac{\partial C_{f}}{\partial t}=\frac{1-R}{1+\lambda} C_{f} \frac{\partial}{\partial x}\left[D_{w}(\theta) \frac{\partial \theta}{\partial x}\right]+\frac{1}{1+\lambda} \frac{\partial}{\partial x}\left(D_{\mathrm{cl}}(\theta) \frac{\partial C_{f}}{\partial x}\right)
$$

The first term in the right-hand side of Eq. (13) represents the convection effect, i.e. chloride ingress caused by water movement and the second term describes the diffusion process due to concentration gradient. Water movement due to capillary absorption is usually described as follows: 


$$
\frac{\partial \theta}{\partial t}=\frac{\partial}{\partial x}\left[D_{w}(\theta) \frac{\partial \theta}{\partial x}\right]
$$

Thus, Eq. (13) can be written as:

$$
\frac{\partial C_{f}}{\partial t}=\frac{1-R}{1+\lambda} \frac{\partial \theta}{\partial t} C_{f}+\frac{1}{1+\lambda} \frac{\partial}{\partial x}\left(D_{\mathrm{cl}}(\theta) \frac{\partial C_{f}}{\partial x}\right)
$$

To sum up, the penetration of chloride ions in an unsaturated concrete is governed by this coupled system of partial differential equation (PDEs), i.e. Eqs. (14) and (15). Moreover, one can clearly see that Eq. (14) and the second term of Eq. (15), representing the two mechanisms of convection and diffusion respectively, have the similar form. Therefore, when the coupled PDEs are applied numerically, two consecutive steps are usually adopted with in a time interval (time step) to solve this problem: the first step is to solve Eq. (14) for water movement; the second step is to solve Eq. (15) following the results of water absorption in the first step to obtain the chloride concentration (Ababneh et al. 2003). It should be pointed out that an iteration process should be used to solve Eq. (14) (the first step) because $D_{w}(\theta)$ is strongly dependent on the relative water content, which will be argued in the following section.

\section{Transport of capillary water}

When concrete is assumed to be fully hydrated, implying no further water consumed during the ingress process, transport of capillary water can be described in terms of volume fraction of pore water by Richards' equation (Ozbolt et al. 2010). The equation for unsaturated flow through porous media is expressed as: condition $\theta=0, x>0, t=0$ (uniform initial water content within the sample of material), Eq. (16) turns into Eq. (14). By applying the Boltzmann's transformation, i.e., introducing the Boltzmann variable, 
$219 \phi=x \cdot t^{-1 / 2}$, the partial differential Eq. (14) can be reduced to an ordinary boundary-value problem

220 (Lockington, et al. 1999):

$221-\frac{1}{2} \phi \frac{d \theta}{d \phi}=\frac{d}{d \phi}\left(D_{w}(\theta) \frac{d \theta}{d \phi}\right)$

222 with $\theta=1$ for $\phi=0$, and $\theta=0$ as $\phi \rightarrow \infty$.

The functional relationship between $D_{w}$ and $\theta$ is strongly non-linear, which is commonly approximated by the exponential-law (Hall 1989; Hall 1994; Lockington et al. 1999):

$$
D(\theta)=D_{0} e^{n \theta}
$$

in which $D_{0}$ and $n$ are empirically-fitted constants. Eq. (18) is widely utilized because of its relatively simple expression and rather narrow range of parameter $n$ (6 to 8 by Hall (1989)). The cumulative water absorption of a sample, $i$, increases as the square root of the elapsed time $t$ :

$$
i=S t^{1 / 2}
$$

in which $S$ is defined as the sorptivity of a porous materials, and regarded as the rate of water uptake by the material when exposed to a water resource. In some literatures, it is also named as the coefficient of capillary suction (Wittmann et al. 2006). Obviously from Eq. (19), $S$ can be easily determined from the slope of the $i$ versus $t^{1 / 2}$ curve, where $i$ is measured in experiment as $i=\Delta w / A \rho_{\mathrm{w}}$ (in which $\Delta w$ is the increase in weight, $A$ the cross-sectional area and $\rho_{\mathrm{w}}$ the density of water). regressed value of $S$ (Lockington et al. 1999). In their method, the constant $n$ is taken a universal value as 6.0 , and then $D_{0}$ can be approximately estimated by:

$$
D_{0}=s^{2} / 123.131
$$


One of the advantages of mesoscale modeling of strongly heterogeneous materials such as concrete is that it can particularly represent the characteristics of interface between different materials. For example, recent studies have began to treat concrete as a three-phase composite material, consisting of coarse aggregates, mortar matrix and the interfacial transition zones (ITZs) between the

\section{Mesoscale structure of concrete}

The size distribution of coarse aggregates in a geometrical domain is generated in terms of the

$$
P_{c}\left(D<D_{0}\right)=P_{k}\left(1.065 D_{0}^{0.5} D_{\max }^{-0.5}-0.053 D_{0}^{4} D_{\max }^{-4}-0.012 D_{0}^{6} D_{\max }^{-6}-0.0045 D_{0}^{8} D_{\max }^{-8}+0.0025 D_{0}^{10} D_{\max }^{-10}\right)
$$
in which $D_{0}$ is one of the aggregate diameter in the gradation series; $P_{k}$ is the volume fraction of coarse aggregate. 
In this study, a standard pseudo-random number generator is used to produce probabilities from

which the diameter of the aggregate is determined. This procedure is repeated until the calculated volume fraction of aggregates by Eq. (22) is obtained. After accomplishing the database of aggregate particles, the particles are randomly placed one by one into the domain of the concrete sample in such a way that there is no overlapping with particles already placed (Grassl and Pearce 2010; Wang et al. 1999). An example of the generated concrete sample by the above procedure is shown in Fig. 3 with coarse aggregate volume fraction of $39.5 \%$ and maximum and minimum diameters of $20 \mathrm{~mm}$ and $4 \mathrm{~mm}$ respectively.

\section{Lattice network model}

In the past few years, it has been proposed that on the mesoscale level, mass transport in concrete can be described by means of lattice-type model. This type of model is categorized as a discrete numerical method and has the advantage of mesh-independence and accurate descriptions of basic properties of the continuum response (Sadouki and Van Mier 1997; Grassl 2009). In our previously published paper (Wang and Ueda 2011), the lattice network model was established to simulate capillary water transport process by concrete on the basis of Voronoi tessellation. Fig. 4 illustrates the composition of lattice network of a concrete specimen on mesoscale. In Fig. 4, polygons with dotted sides are the Voronoi elements after meshing the specimen. By connecting the nodes in Voronoi diagram (nuclei of Voronoi polygons and the intermediate points on edges of the Voronoi polygons), a network with five types of lattice elements is established with respect to their position falling in the mesostructure of concrete (see Fig. 4a). Each type of lattice element has their unique transport property. When concrete is damaged due to mechanical loading or environmental action

(e.g., freeze and thaw cycling), cracks are always supposed to generate and propagate along the joint edge of two neighbouring Voronoi elements (see Fig. 4b). In other words, the cracks are only 
allowed to present on the dotted lines. It should be pointed out that the 3-D configuration of cracks is not considered due to the 2-D analysis nature. Therefore, in the present approach, the crack depth perpendicular to mass moving direction is assumed to be same with thickness of the specimen, which was usually set as unit thickness. As a result, the lattice elements along cracks will be given their cross-sectional area and diffusivity in terms of the crack openings. Only an overview of this approach is briefly given here. Additional details, such as those related to Voronoi element construction, lattice element meshing method and the discrete form of governing equation have been reported by Wang et al. (2008) and Wang and Ueda (2011).

The use of an irregular lattice network for the description of water movement in uncracked concrete has been successfully implemented (Wang and Ueda, 2011). In the current work, the effect of cracks caused by FTCs attack is under the consideration.

\section{Chloride penetration of undamaged concrete}

\section{Chloride diffusion coefficient of the ITZ}

As already mentioned, chloride ions penetrate faster in the ITZ than in the bulk cement paste. Numerous studies have been carried out to investigate and quantify the effect of ITZs on the transport properties of mortar and concrete. The diffusion coefficients of the ITZ, as well as its thickness obtained from the literatures are listed in Table 1. Although their conclusions are not in full agreement with each other, it can be generally summarized that $D_{\text {ITZ }}$ is usually less than 16 times of that of cement paste, especially in most cases no more than 10 times. Moreover, because the diffusion coefficient of mortar has the same magnitude of order as that of cement paste (Caré

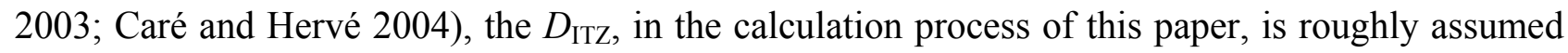
as 10 times of that corresponding to mortar. It means that the diffusion coefficient for lattice 
elements on the aggregate-mortar boundary is taken as 10 times higher than that for the lattice

310 elements within mortar.

\section{Numerical example- initial and boundary conditions}

The modeling approach described above, which was implemented by $\mathrm{C}++$ language and performed on a personal computer on Windows, is applied to a $\mathrm{NaCl}$ solute absorption problem. The experimental study on this numerical example has been performed by Wittmann et al. (2006) to investigate the freezing-thawing damage on water and chloride transport properties of concrete. In the current analysis, the water-to-cement ratio is assumed to be 0.6 in order to coincide with that the illustration of boundary condition, is shown in Fig. 5, which is modeled with 844 Voronoi elements and 8961 lattice elements (but for sake of clearness, the lattice elements are not depicted).

In the experimental program, concrete cubic specimens with an edge length of $100 \mathrm{~mm}$ were cut into two halves (i.e. the thickness of each slice is $50 \mathrm{~mm}$ ). After adequately cured in the humid curing room, the samples were further stored under laboratory conditions at $20 \pm 3{ }^{\circ} \mathrm{C}$ and $50 \% \mathrm{RH}$ for another 21 days. And then, they were dried in an aerated oven at a temperature of $50^{\circ} \mathrm{C}$ for 24 penetration test, the four lateral sides of the slice were sealed with wax in order to have one directional flow from the bottom surface through the specimen. The schematic representation of the experimental set-up can be referred to Wittmann et al. (2006). To fit the test conditions, the bottom and top surfaces of the specimen are treated to be exposed to chloride solution and to fully dried atmosphere respectively, whereas the two side surfaces are completely sealed. In terms of the above 
drying procedure and thin thickness of the slice, the sample can be assumed to fully dried before contacting to water solution. As a result, the initial and boundary condition for transport of capillary water are taken as follows: $\theta(x)=0.0$, for $t=0 ; \theta\left(x_{b}\right)=1.0$, for $t>0 ; x_{b}$ is the coordinate of the nodes of lattice elements that are exposed to the solution. It implies that on the exposed surface, concrete is assumed to be fully saturated. Therefore, the chloride concentration on the exposed surface was determined as $4.86 \times 10^{-3} \mathrm{~g} / \mathrm{cm}^{3}$ for undamaged concrete in terms of the concrete porosity, which was estimated as $26.7 \%$ with $w / c=0.6$ by means of the Powers' model (Hansen 1986). It was kept constant in the 24 hours' analysis by assuming that the $3 \% \mathrm{NaCl}$ solution (with chloride concentration in the solution of $1.82 \times 10^{-2} \mathrm{~g} / \mathrm{cm}^{3}$ ) completely fill in the pores at the very thin surface layer of concrete. It should be noted that the chloride concentration on the exposed surface, is varied with the damage degree of concrete because the damage can result in a porosity increase. In addition, from the test data of all samples, constant chloride content $(0.07 \%$ by weight of concrete $)$ was observed in deep position along penetration direction, at which the chlorides were unreachable in 24 hours. This implies that initial chloride content was present in the concrete mixture, which was estimated to be $1.68 \times 10^{-3} \mathrm{~g} / \mathrm{cm}^{3}$ if the concrete density is taken $2.4 \mathrm{~g} / \mathrm{cm}^{3}$. To summarize, for chloride transport, the initial and boundary conditions are: $C_{f}(x)=1.68 \times 10^{-3} \mathrm{~g} / \mathrm{cm}^{3}$ for $t=0$, which was observed from the experimental results; $C_{f}\left(x_{b}\right)=4.86 \times 10^{-3} \mathrm{~g} / \mathrm{cm}^{3}$ of concrete, for $t>0$. The filter effect, making the chloride front slower than water penetration, is also taken into account with the coefficient of $R=0.7$.

\section{Predicted result of the chloride profile}

As the water absorption have been analyzed in a previous paper (Wang and Ueda, 2011), only the distribution of chloride will be argued here, and shown in Fig. 6. The effect of coarse aggregates on the chloride penetration front can be clearly observed in the penetration area: on one hand, the 
coarse aggregates, especially those with relatively larger size can "block" the moving chlorides due to their lower permeability; on the other hand, the presence of ITZs, which have higher porosity, will contribute to facilitating the penetration of chlorides. Therefore, from Fig. 6, one can see that the chloride concentration in the area behind coarse aggregates is much lower than that in the area of surrounding mortar matrix. This phenomenon has been experimentally observed and considered to cause the scatter in the depths of chloride penetration even within the same sample (Rodriguez and Hooton 2003)

Fig. 7 provides the comparison of chloride profiles in concrete between the predicted results by the lattice network model and the experimental data obtained by Wittmann et al. (2006). It can be seen that in this example, after $24 \mathrm{hrs}$ exposure to $\mathrm{NaCl}$ solution, the predicted chloride profile is in good agreement with the experimental measurement.

\section{Chloride Penetration of Freeze-thaw damaged concrete}

\section{Cracks induced by freeze-thaw cycling}

Recent studies have shown that subjecting to freeze-thaw damage can result in the increase of permeability of concrete due to the occurrence of new cracks and connectivity of originally existing microcracks (Jacobsen et al. 1996; Yang et al. 2006). For example, Jacobsen et al. (1996) observed that the freeze-thaw cycling can increase the chloride penetration rate up to about 2.5 to 8 times after 31 to 95 FTCs when compared with the undamaged concrete. It also indicates that the internal cracking of concrete induced by freeze-thaw cycling is significantly dependent on the number of cycles. Therefore, after different FTCs, the knowledge on internal cracks, e.g., the crack distribution (numbers and location) and crack width should be investigated and made clear so as to estimate their effects on chloride transport.

Contrary to the research effort on freeze-thaw mechanism, it seems that in the past, studies on 
the characteristics of FTC-induced cracks were mostly focused on the qualitative interpretation, but few could give a precise and quantitative description of the cracks. For instance, Jacobsen et al. (1996) performed the rapid freeze-thaw experiment on a non-air entrained concrete with w/c of 0.4 and measured an ultimate volume increase as $2.9 \%$ after 95 FTCs by weighing the frosted specimen in air and water respectively. Hasan et al. (2004) conducted a freezing-thawing test on the non-air entrained concrete $(\mathrm{w} / \mathrm{c}=0.5)$ in a climate chamber. In this experiment, the strain variation, defined as the plastic tensile strain, was measured during the freezing-thawing process and regarded as the evaluation of damage degree. Therefore, for the purpose of application of numerical models, it is necessary to convert the above test measurements into the cracking information.

For a prismatic specimen with the initial size of $V_{0}=L_{1} \times L_{2} \times L_{3}$, the increase length of each side due to freeze-thaw cycling is set as $\Delta L_{1}, \Delta L_{2}$ and $\Delta L_{3}$, then the increased volume $\Delta V$ may be calculated as:

$$
\Delta V=\left(L_{1}+\Delta L_{1}\right)\left(L_{2}+\Delta L_{2}\right)\left(L_{3}+\Delta L_{3}\right)-V_{0}
$$

Then the ratio of volume increase is written as:

$$
\frac{\Delta V}{V_{0}}=\frac{\left(L_{1}+\Delta L_{1}\right)\left(L_{2}+\Delta L_{2}\right)\left(L_{3}+\Delta L_{3}\right)}{L_{1} L_{2} L_{3}}-1=\left(1+\frac{\Delta L_{1}}{L_{1}}\right)\left(1+\frac{\Delta L_{2}}{L_{2}}\right)\left(1+\frac{\Delta L_{3}}{L_{3}}\right)-1
$$

Here, a uniform assumption is typically given that freeze-thaw cycling may cause the same expansion along each direction. Thus the above equation can be written as:

$$
\frac{\Delta V}{V_{0}}=(1+\varepsilon)(1+\varepsilon)(1+\varepsilon)-1=(1+\varepsilon)^{3}-1
$$
in which $\varepsilon$ is the plastic strain induced by freeze-thaw cycling in any direction. Reversely, according to Eq. (25), when the volume increase is measured, the plastic strain of a specimen can be estimated as:

$$
\varepsilon=\sqrt[3]{1+\frac{\Delta V}{V_{0}}}-1
$$


The volume increase and plastic strain derived from experimental data (Hasan et al. 2004;

401 Jacobsen et al. 1996) based on Eq. (26) are given in Table 2, together with their originally measured results.

From Table 2 it can be observed that results from the two tests differ too much up to an order-of-magnitude variation. The most significant reason seems to be attributed to the different freezing-thawing process and deformation measuring method as explained above. However, it should be noted that in Jacobsen et al.'s experiment, not only the volume increase was measured but also the crack density and crack width were also evaluated with the scanning electron microscope (SEM). Further more, the calculated crack width using the measured volume increase, as shown in Table 2, was proved to be in good accordance with the SEM observation (Jacobsen et al. 1995). And recently, a similar crack width magnitude order was also observed by using the SEM technology 411 (Yang et al. 2006). Therefore, in this study, the width of FTC-induced cracks will be determined 412 based on experimental data obtained by Jacobsen et al. (1996). cracks mostly occur in the interface between cement paste and aggregate (Jacobsen et al. 1995; 1996; Yang et al. 2006). Based on this fact, in the lattice network model, all the cracks are assumed to be present around the coarse aggregates and the cross-sectional area of lattice elements on the ITZs (see Fig. 4) will be adjusted according to the crack width. And then the corresponding 419 the following sections. The influence of FTC-induced cracking and the above modeling method 420 have been demonstrated in a previous paper in terms of a pure diffusion process of chloride under 421 saturated condition (Wang and Ueda 2009). It was found that the diffusion coefficient of concrete after frost attack is increased with the increase of freezing-thawing cycles. 
Because few attempts have been done to quantify the process for water transport through a single

441 The parameters used for numerical simulation of water and chloride transport through

442 freezing-thawing damaged concrete are summarized in Table 3. The contacting time of sample to 443 water is assumed as 24 hrs long. Wittmann et al. (2006) conducted the research on water and 444 chloride penetration in concrete after 50 and 150 FTCs, so that their experimental data will be used 
to verify the numerical result. After subjected to 50 and 150 FTCs, the width of microcracks within concrete is taken as $8 \mu \mathrm{m}$ and $15 \mu \mathrm{m}$ respectively, which are deduced from the observation of Jacobsen et al (1996). The distribution of water content over the depth of the specimen after 8 and 24 hrs' exposure is shown in Fig. 8. Moreover, the numerical results of cumulative absorbed water for concrete samples after different FTCs are compared with the experiment data and depicted in Fig. 9. It can be seen that the penetration of water is much faster and deeper in cracked than in un-cracked concrete. The amount of up-taken water by the sample is found to increase with the increase of FTCs, which is in good agreement with experimental observation. This result can be attributed to the formation of more penetration paths and connectivity of the initial microcracks when subjected to the action of freezing-thawing. To further illustrate this phenomenon, the relationship between water content $\theta$ and Boltzmann variable $\phi$ of concrete subjected 50 and 150 FTCs, as well as that without damage, is shown in Fig. 10. It is noted that at the same value of Boltzmann variable, the water content has a notable increase after subjected to freeze-thaw cycling.

Similarly, Fig. 11 shows the comparison of the model predictions and experimental results for the chloride profiles after 50 and 150 FTCs. Comparing the distribution of chlorides after subjecting to different FTCs (see Figs. 7 and 11), it can be seen that the chlorides penetrate deeper with increase of FTCs. A similar conclusion was drawn in experiments (Wittmann et al. 2006). The agreement between the prediction of numerical model and test data illustrates that the lattice network model, combined with the foregoing formulation in this paper, can successfully simulate the chloride penetration in unsaturated, FTC-damaged concrete.

\section{Summary and Conclusions}

In the present paper, a numerical simulation approach in mesoscale with the lattice network model is reported to evaluate the chloride ions penetration process within unsaturated concretes before and 
after subjected to the freezing-thawing cycles (FTCs). The following conclusions can be drawn:

1) In the mesoscale, concrete is represented as a three-phase composite, i.e., the mortar matrix, aggregate particles and interfacial transition zones (ITZs), so that it is possible to involve separate material models (e.g., transport model) for each phase. The strategy of Voronoi diagram is adopted that is able to account for the damage or cracking with the concept of discrete cracks. On the basis of Voronoi tessellation of a concrete domain (uncracked or cracked), an irregular network composing of various types of lattices is built up to describe the water and chlorides transport.

2) Under unsaturated state, chloride penetration in concrete is attributed to two mechanisms, i.e. convection (water absorption) and diffusion. The mathematical formulation of this combined process is proposed and implemented into the lattice network, and then solved by two consecutive steps separately.

3) FTC-induced damage can be represented by a uniformly distributed and connected crack network throughout the concrete. As a result, both the water absorption and chloride penetration will be accelerated after subjected to FTCs. In this study, the features of microcracks, including crack distribution and widths, are clarified by investigating and analyzing the available experimental observations. After applying the lattice network model to the FTC-damaged concrete, the distribution of water and chloride over the depth of the specimen are quantitatively obtained. It is observed that the penetration of water and chloride is faster and deeper in damaged than in undamaged concrete. The damage of concrete also significantly increases the amount of up-taken water.

4) The lattice network model, coupled with the mesoscale structure of concrete, seems to provide a realistic tool for simulating the chloride penetration process in intact or damaged concrete 
material since the predicted chloride profiles agree well with experimental data. Therefore, it may be hoped that the attempt in this paper could be helpful to reduce the experimental time and

\section{Acknowledgements}

This study was supported by the National Natural Science Foundation of China (Grant No.

Ababneh, A., Benboudjema, F. and Xi, Y. (2003). "Chloride penetration in nonsaturated concrete.” J. Mater. Civil Eng., 15(2), 183-191.

Akita, H., Fujiwara, T. and Osaka, Y. (1994). “An analytical method of moisture transfer within concrete due to drying.” J. Mater. Concr. Struct. Pav., 23(490), 101-110. (in Japanese)

Aldea, C-M., Shah, S. P. and Karr, A. (1999). "Effect of cracking on water and chloride permeability of concrete.” J. Mater. Civil Eng., 11(3), 181-187.

Bentz, D. P., Detwiler, R. J., Garboczi, E. J., Halamickova, P. and Schwartz, L. M. (1997). "Muti-scale modeling of the diffusivity of mortar and concrete." In: L.O. Nilsson and J. P. Ollivier, Eds., Proc. of Chloride Penetration into Concrete, Saint-Rémy-lès-Chevreuse, France, RILEM 
514 Boddy, A., Bentz, E., Thomas, M. D. A. and Hooton, R. D. (1999). “An overview and sensitivity 515 study of a multimechanistic chloride transport model.” Cem. Concr. Res., 29(6), 827-837.

516 Breton, D., Ollivier, J. P. and Ballivy, G. (1992). "Diffusivity of chloride ions in the transition zone 517 between cement paste and granite." In: J. C. Maso, Ed., Interfaces between Cementitious 518 Composites, E \& F. N. Spon, London, 279-288.

519 Caré, S. (2003). "Influence of aggregates on chloride diffusion coefficient into mortar." Cem. Concr. 520 Res., 33(7), 1021-1028.

521 Caré, S. and Hervé, E. (2004). "Application of an n-phase model of the diffusion coefficient of 522 chloride in mortar.” Transport Porous Med., 56(2), 119-135.

Delagrave, A., Marchand, J. and Samson, E. (1996). "Prediction of diffusion coefficients in cement-based materials on the basis of migration experiments." Cem. Concr. Res., 26(12), 1831-1842.

Climent, M. A., de Vera, G., Lopez, J. F., Viqueira, E., and Andrade, C. (2002). "A test method for measuring chloride diffusion coefficients through nonsaturated concrete. Part I: The instantaneous plane source diffusion case." Cem. Concr. Res., 32(7), 1113-1123. measuring chloride diffusion coefficients through partially saturated concrete. Part II: The instantaneous plane source diffusion case with chloride binding consideration." Cem. Concr. Res., 37(5), 714-724.

533 Djerbi, A., Bonnet, S., Khelidj, A. and Baroghel-bouny, V. (2008). "Influence of traversing crack on chloride diffusion into concrete." Cem. Concr. Res., 38(6), 877-883. 
permeability of concrete under tension." Mater. Struct., 29(3), 141-151.

537 Grassl, P. (2009). "A lattice approach to model flow in cracked concrete." Cem. Concr. Compos., 31(7), 454-460.

Grassl, P. and Pearce, C. (2010). "Mesoscale approach to modeling concrete subjected to thermomechanical loading." J. Eng. Mech., 136(3), 322-328.

Hall, C. (1989). "Water sorptivity of mortar and concretes: a review." Mag. Concr. Res., 41(147), $51-61$

Hall, C. (1994). "Barrier performance of concrete: A review of fluid transport theory." Mater. Struct., 27(2), 291-306.

Hansen, T. C. (1986). "Physical structure of hardened cement paste: a classical approach". Mater. Struct., 19(114), 423-436.

Hasan, M., Okuyama, H., Sato, Y. and Ueda, T. (2004). "Stress-strain model of concrete damaged by freezing and thawing cycles.” J. Adv. Concr. Tech., 2(1), 89-99.

Ishida, T., Iqbal, P. O. N. and Anh, H. T. L. (2009). "Modeling of chloride diffusivity coupled with non-linear binding capacity in sound and cracked concrete." Cem. Concr. Res., 39(10), 913-923.

Ismail, M., Toumi, A., Francois, R. and Gagne, R. (2008). "Effect of crack opening on the local diffusion of chloride in cracked mortar samples." Cem. Concr. Res., 38(8-9), 1106-1111.

Jacobsen, S., Gran, H. C., Sellevold, E. J. and Bakke, J. A. (1995). "High strength concrete-freeze/thaw testing and cracking." Cem. Concr. Res., 25(8), 1775-1780.

Jacobsen, S., Marchand, J. and Boisvert, L. (1996). "Effect of cracking and healing on chloride transport in OPC concrete." Cem. Concr. Res., 26(6), 869-881.

Jaffer, S. J. and Hansson, C. M. (2008). "The influence of cracks on chloride-induced corrosion of steel in ordinary Portland cement and high performance concretes subjected to different loading 
conditions." Corr. Sci., 50 (12), 3343-3355.

560 Kato, Y. and Uomoto, T. (2005). "Modeling of effective diffusion coefficient of substances in 561 concrete considering spatial properties of composite materials." J. Adv. Concr. Tech., 3(2), 241-251.

562 Kelham, S. (1988). “A water absorption test for concrete.” Mag. Concr. Res., 40(143), 106-110.

563 Lockington, D., Parlange, J. -Y. and Dux, P. (1999). "Sorptivity and the estimation of water 564 penetration into unsaturated concrete." Mater. Struct., 32(5), 342-347.

565 Lunk, P. (1998). "Penetration of water and salt solutions into concrete by capillary suction.” J. of 566 Restor. Build. Monu., (4), 399-422.

567 McCarter, W. J., Ezirim, H. and Emerson, M. (1992). "Absorption of water and chloride into 568 concrete.” Mag. Concr. Res., 44(158), 31-37.

569 Nagesh, M. and Bhattacharjee, B. (1998). "Modelling of chloride diffusion in concrete and 570 determination of diffusion coefficients.” ACI Mate. J., 95(2), 113-120.

571 Nakamura, H., Srisoros, W., Yashiro, R. and Kunieda, M. (2006). "Time-dependent structural 572 analysis considering mass transfer to evaluate deterioration process of RC structures." J. Adv. Concr. 573 Tech., 4(1), 147-158.

574 Neithalath, N. (2006). "Analysis of moisture transport in mortars and concrete using 575 sorption-diffusion approach.” ACI Mate. J., 103(3), 209-217.

576 Nielsen, E. and Geiker, M. R. (2003). "Chloride diffusion in partially saturated cementitious material." Cem. Concr. Res., 33(1), 133-138.

578 Oh, B. H. and Jang, S. Y. (2004). "Prediction of diffusivity of concrete based on simple analytic 579 equations." Cem. Concr. Res., 34(3), 463-480.

580 Ozbolt, J., Balabanic, G., Periskic, G. and Kuster, M. (2010). "Modelling the effect of damage on 581 transport processes in concrete." Constr. Build. Mater., 24(9), 1638-1648. 
Qi, C. (2003). "Quantitative assessment of plastic shrinkage cracking and its impact on the

583

584

585

586

587

588

589

590

591

592

593

594

595

596

597

598

599

600

601

602

603

604

corrosion of steel reinforcement.” Ph.D thesis, Purtue Univ., West Lafayette, Ind.

Rodriguez, O. G. and Hooton, R. D. (2003). "Influence of cracks on chloride ingress into concrete." ACI Mater. J., 100(2), 120-126.

Roelfstra, G., Hajdin, R., Adey, B. and Bruhwiler, E. (2004). "Condition evolution in bridge management systems and corrosion-induced deterioration.” J. Brid. Eng., 9(3), 268-277.

Sadouki, H. and Van Mier, J.G. M. (1997). "Meso-level analysis of moisture flow in cement composites using a lattice-type approach.” Mater. Struct., 30(10), 579-587.

Saeki, T. and Niki, H. (1996). "Migration of chloride ions in non-saturated mortar." Proc. Japan Concr. Ins., 18(1), 963-968. (in Japanese)

Saetta, A. V., Scotta, R. V. and Vitaliani, R. V. (1993). "Analysis of chloride diffusion into partially saturated concrete.” ACI Mater. J., 90(5), 441-451.

Sahmaran, M. (2007). "Effect of flexure induced transverse crack and self-healing on chloride diffusivity of reinforced mortar.” J. Mater. Sci., 42 (22), 9131-9136.

Sahmaran, M., Li, M. and Li V. C. (2007). "Transport properties of engineered cementitious composites under chloride exposure.” ACI Mater. J., 104(6), 604-611.

Schiessl, P. and Raupach, M. (1997). "Laboratory studies and calculations on the influence of crack width on chloride-induced corrosion of steel in concrete.” ACI Mater. J., 94 (1), 56-62.

Shane, J. D., Mason, T. O., Jennings, H. M., Garboczi, E. J. and Bentz, D. P. (2000). "Effect of the interfacial transition zone on the conductivity of Portland cement mortar." J. Amer. Ceram. Soc., 83(5), 1137-1144.

Takewaka, K., Yamaguchi, T. and Maeda, S. (2003). "Simulation model for deterioration of concrete structures due to chloride attack." J. Adv. Concr. Tech., 1(2), 139-146. 
605 Ueda, T., Hasan, M, Nagai, K., Sato, Y. and Wang, L. (2009). "Mesoscale simulation of influence 606 of frost damage on mechanical properties of concrete." J. Mater. Civil Eng., 21(6), 244-252.

607 Walravent, J. C. and Reinhard, H. W. (1981). "Theory and experiments on the mechanical behavior 608 of cracks in plain and reinforced concrete subject to shear loading." HERON, 26(1), 1-68.

609 Wang, K., Jansen, D. C. and Shah, S. P. (1997). "Permeability study of cracked concrete." Cem. 610 Concr. Res., 27(3): 381-393.

611 Wang, L. C., Soda, M. and Ueda, T. (2008). "Simulation of chloride diffusivity for cracked concrete 612 based on RBSM and truss network model.” J. Adv. Concr. Tech., 6(1), 143-155.

613 Wang, L. C. and Ueda, T. (2009). "Mesoscopic simulation of chloride ions diffusion in 614 frost-damaged concrete.” Int. J. Model., Ident. Control., 7(2), 148-154.

615 Wang, L. C. and Ueda, T. (2011). "Mesoscale modeling of water penetration into concrete by 616 capillary absorption.” Ocean Eng., 38(4), 519-528.

617 Wang, Z. M., Kwan, A. K. H. and Chan, H. C. (1999). "Mseoscopic of study of concrete I: 618 Generation of random aggregate structure and finite element mesh.” Comp. struct., 70(5), 533-544.

619 Wittmann, F. H., Zhang, P. and Zhao, T. (2006). "Influence of combined environmental loads on 620 durability of reinforced concrete structures.” Restor. Build. Monu., 12(4), 349-362.

621 Yang, C. C. (2003). "Effect of the interfacial transition zone on the transport and the elastic 622 properties of mortar." Mag. Concr. Res., 55(4), 305-312.

623 Yang, Z., Weiss, W. J. and Olek, J. (2006). "Water transport in concrete damaged by tensile loading 624 and freeze-thaw cycling." J. Mater. Civil Eng., 18(3), 424-434. 
Fig.1. Relationship between relative humidity $(\mathrm{RH})$ and normalized water content $\theta$

Fig. 2. Comparison of models on chloride diffusion coefficient versus water content

Fig. 3. The 2-D mesoscale model of a concrete cube

Fig. 4. Demonstration of the construction of the lattice network model

Fig. 5. Specimen model (width $\times$ height $=50 \mathrm{~mm} \times 60 \mathrm{~mm}$ )

Fig. 6. Distribution of chloride (wt\% of concrete) over the section of the specimen after 24 hrs

Fig. 7. Comparison of chloride profiles between test data and numerical result

Fig. 8. Distribution of water content in concrete after subjected to 0, 50 and 150 FTCs

Fig. 9. Amount of water absorbed by the concrete after subjected to 0,50 and 150 FTCs

Fig. 10. Relationship between water content $\theta$ and Boltzmann variable $\phi$

Fig. 11. Comparison of chloride profiles after subjected to 50 and 150 FTCs 


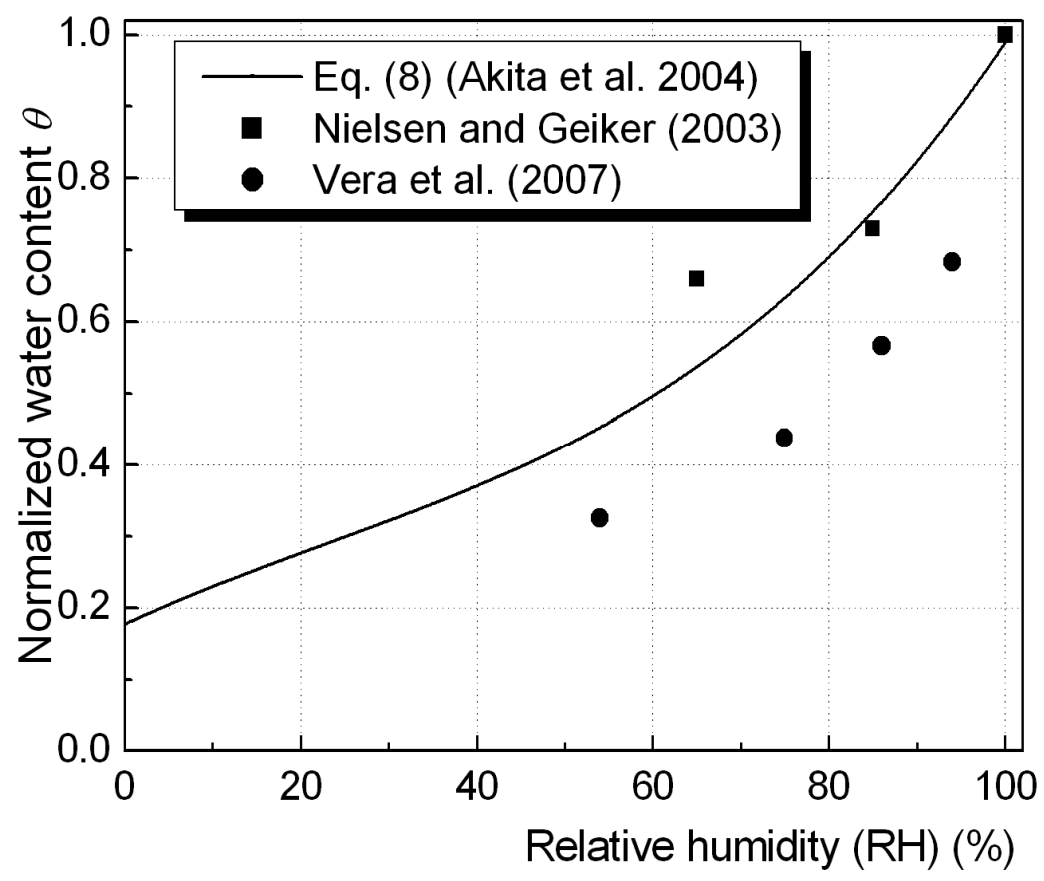

Fig. 1. Relationship between relative humidity (RH) and normalized water content $\theta$ 


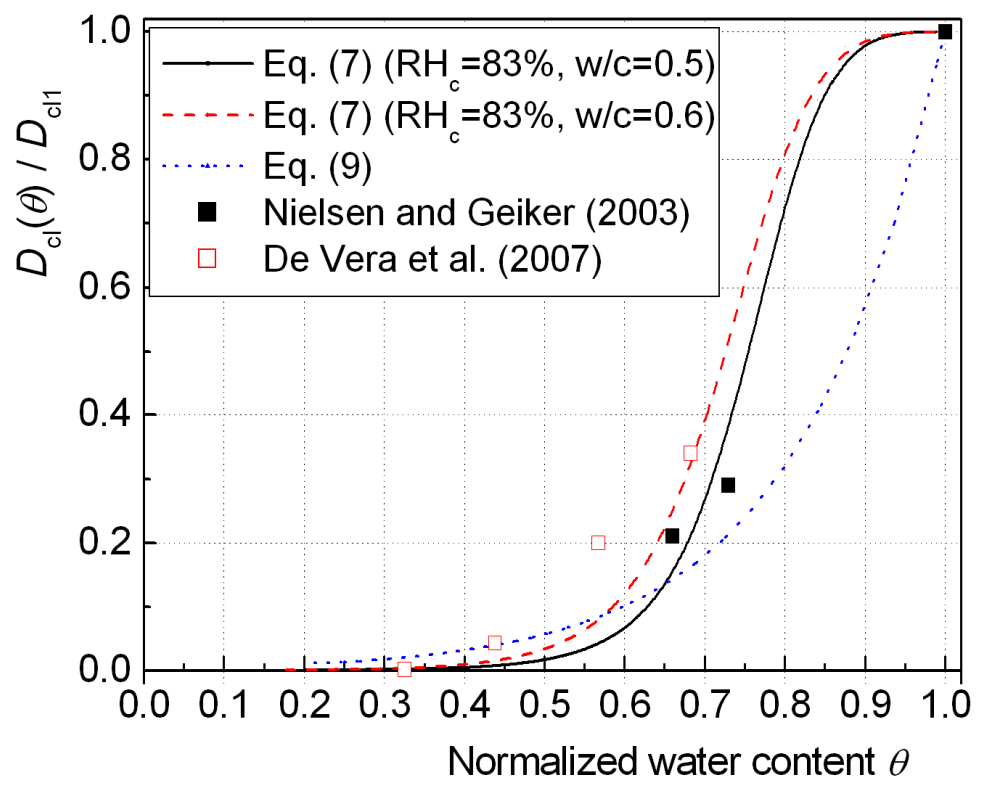

Fig.2. Comparison of models on chloride diffusion coefficient versus water content 


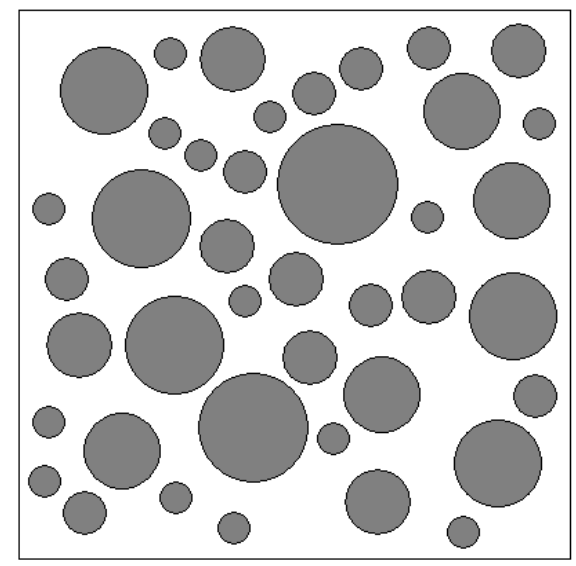

Fig. 3. The 2-D mesoscale model of a concrete cube 


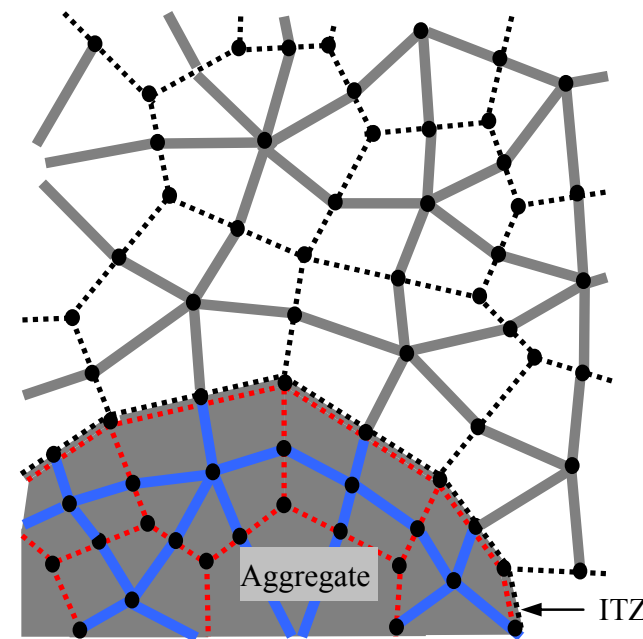

(a) Lattice network of a concrete domain

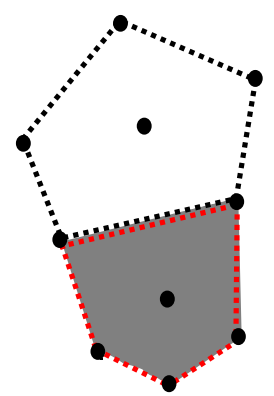

(b) Voronoi elements

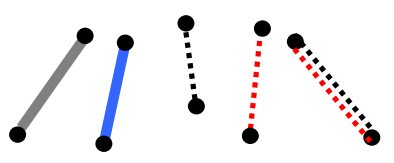

(c) Lattice elements

Fig. 4. Demonstration of the construction of the lattice network model 


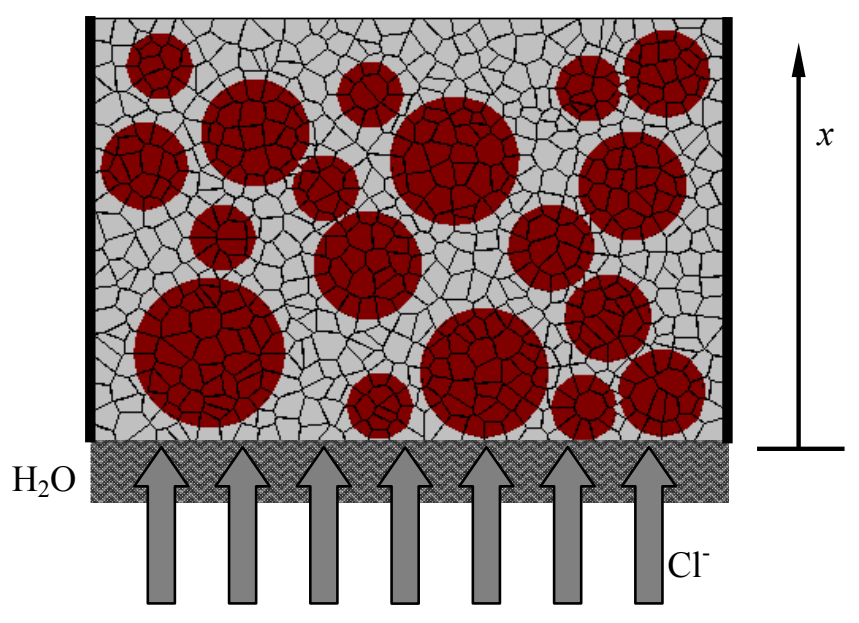

Fig. 5. Specimen model (width $\times$ height $=50 \mathrm{~mm} \times 60 \mathrm{~mm}$ ) 


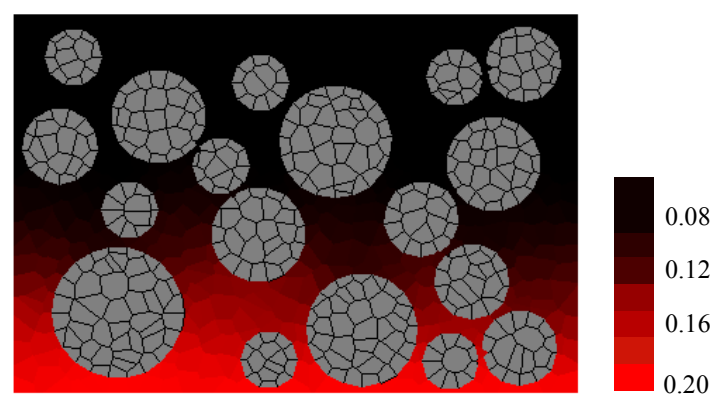

Fig. 7. Distribution of chloride (wt $\%$ of concrete) over the section of the specimen after $24 \mathrm{hrs}$ 


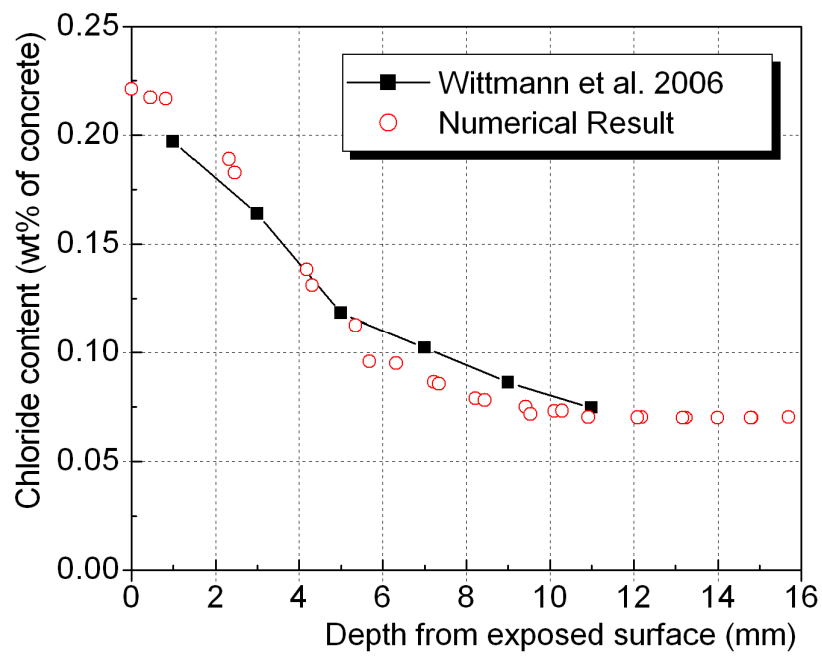

Fig. 8. Comparison of chloride profiles between test data and numerical result 


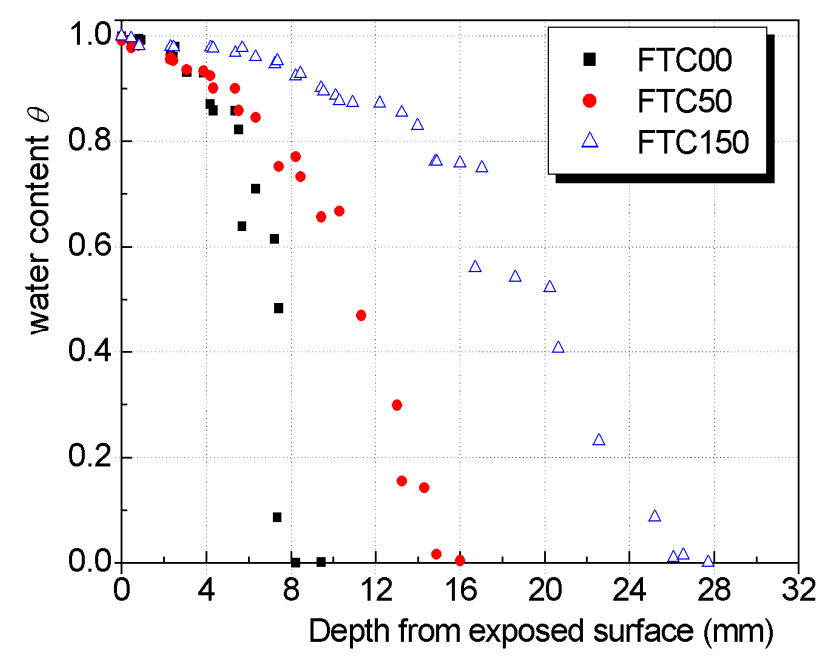

(a) Exposed time $=8 \mathrm{hrs}$

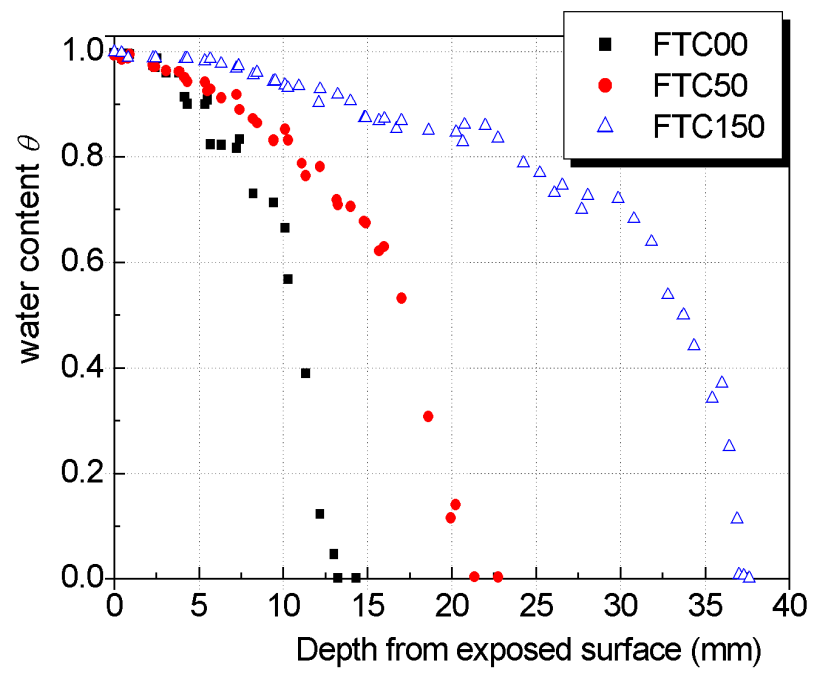

(b) Exposed time $=24 \mathrm{hrs}$

Fig. 9. Distribution of water content in concrete after subjected to 0,50 and 150 FTCs 


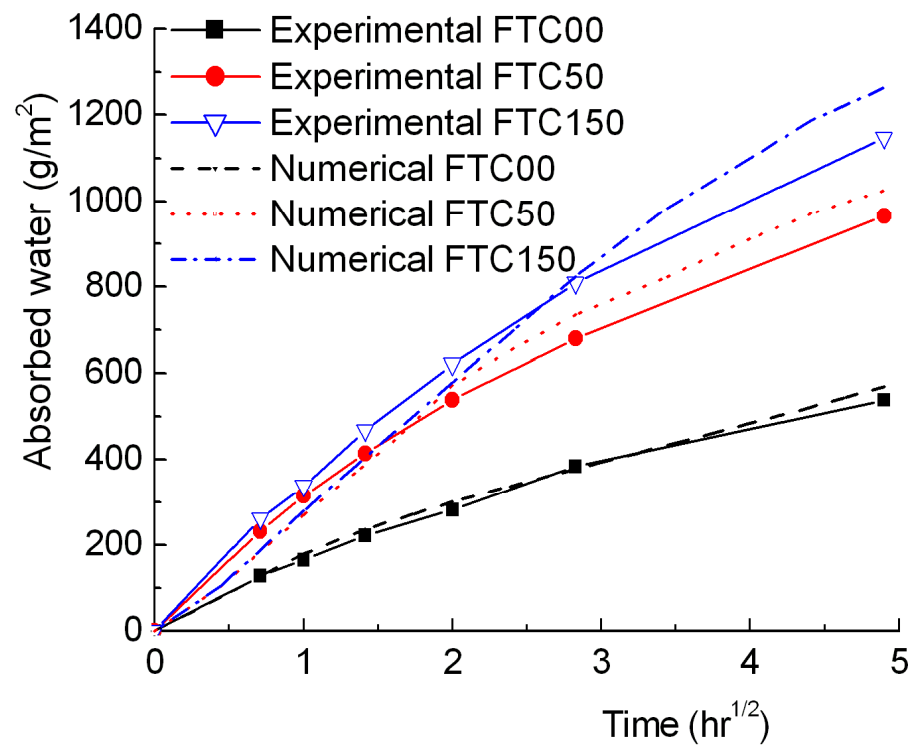

Fig. 10. Amount of water absorbed by the concrete after subjected to 0,50 and 150 FTCs 


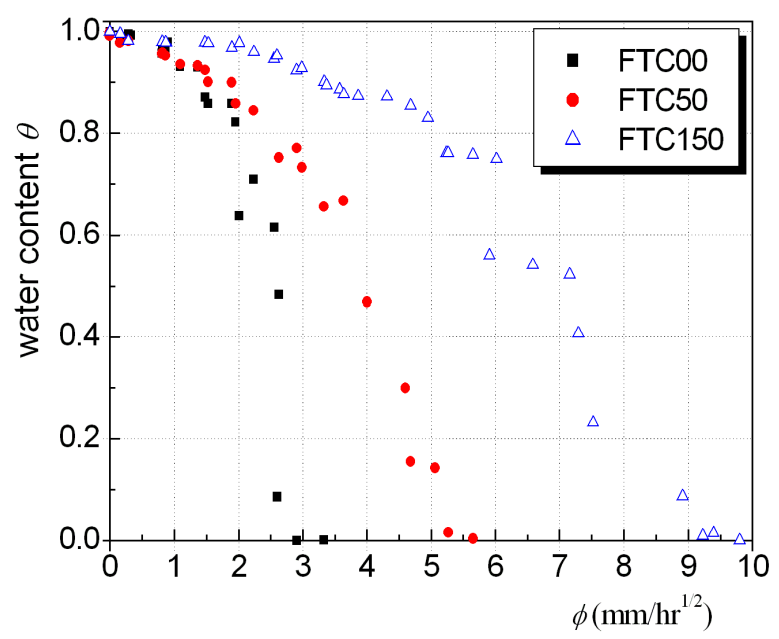

(a) Exposed time $=8 \mathrm{hrs}$

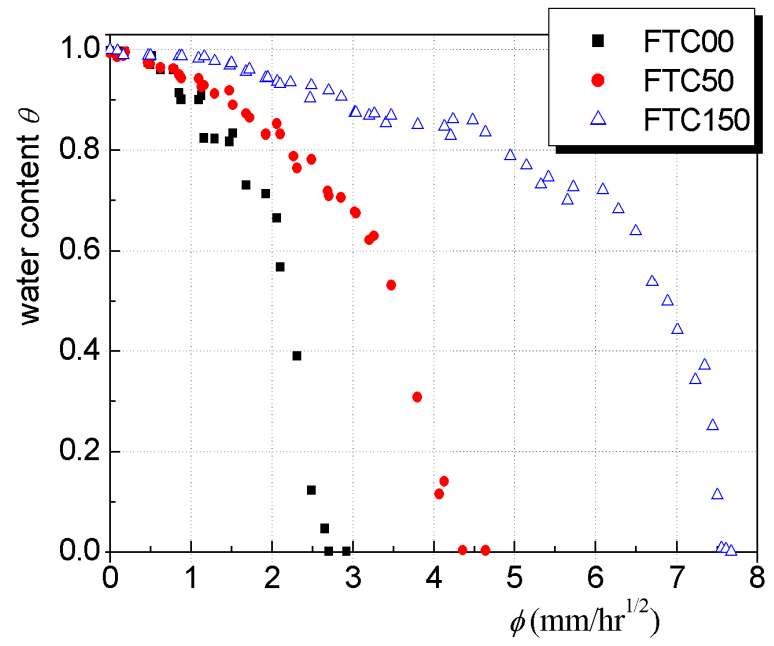

(b) Exposed time $=24 \mathrm{hrs}$

Fig. 11. Relationship between water content $\theta$ and Boltzmann variable $\phi$ 


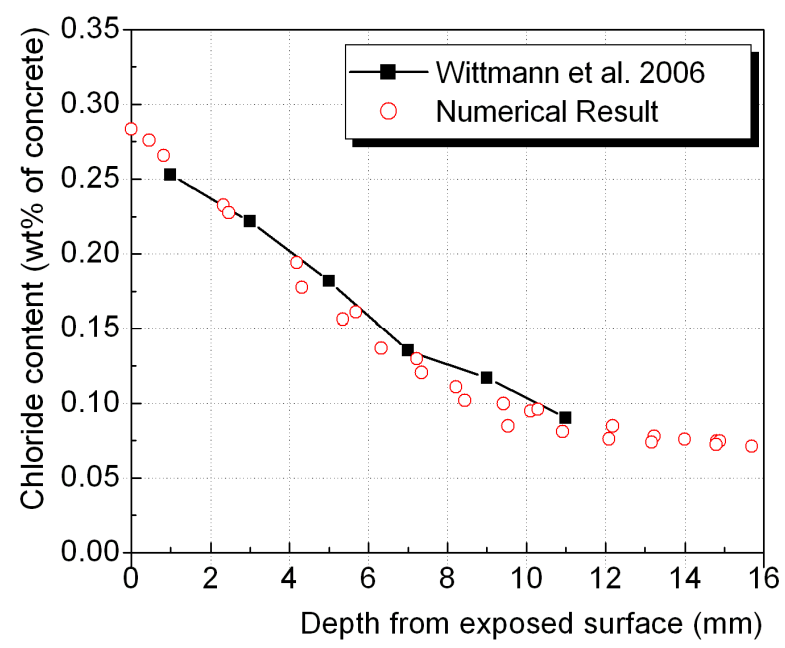

(a) $50 \mathrm{FTCs}$

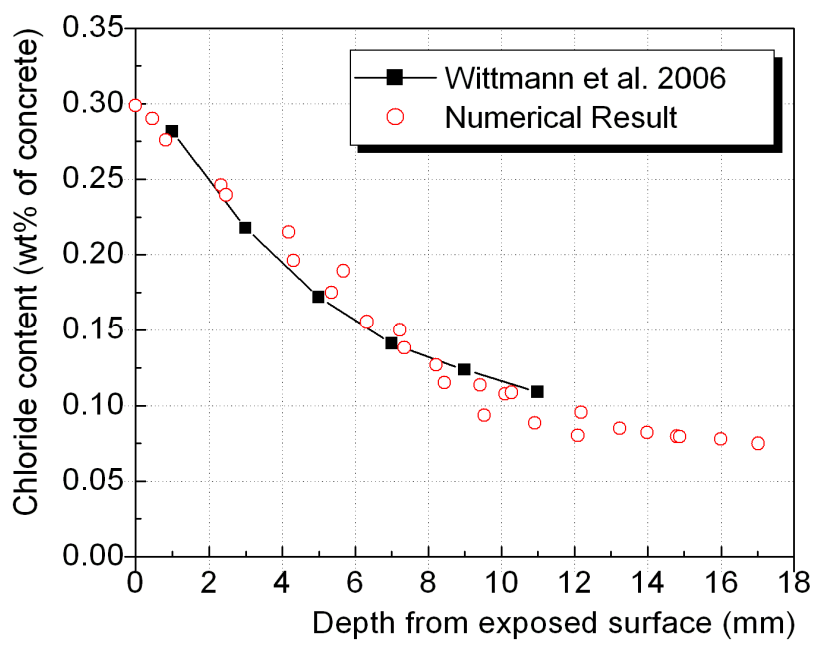

(b) 150 FTCs

Fig. 12. Comparison of chloride profiles after subjected to 50 and 150 FTCs 
Table 1 Literatures summary on the $D_{\text {ITZ }}$

\begin{tabular}{cccc}
\hline Series & Thickness of ITZ $(\mu \mathrm{m})$ & $D_{\mathrm{ITZ}} / D_{\mathrm{p}}$ & Reference \\
\hline 1 & $20-40$ & $1.6-1.3$ & Yang 2003 \\
2 & 30 & 16.2 & Caré and Herve 2004 \\
3 & $10-30$ & 5 & Delagrave et al. 1997 \\
4 & 20 & $4-8$ & Oh and Jang 2004 \\
5 & - & $6-12$ & Breton et al. 1992 \\
6 & 20 & $2-6$ & Bentz et al. 1997 \\
7 & $15-30$ & $2-7$ & Shane et al. 2000 \\
\hline
\end{tabular}

Table 2 Comparison of the strain and crack width from different tests

\begin{tabular}{|c|c|c|c|c|}
\hline \multirow{2}{*}{ Ref. } & \multirow{2}{*}{ Index } & \multicolumn{3}{|c|}{ Number of FTCs } \\
\hline & & 31 & 61 & 95 \\
\hline \multirow{3}{*}{$\begin{array}{c}\text { Jacobsen et } \\
\text { al. } 1996\end{array}$} & $\Delta \mathrm{V} / \mathrm{V}_{0}($ vol- $\%)$ & 0.7 & 1.7 & 2.9 \\
\hline & $\varepsilon\left(\times 10^{-6}\right)^{*}$ & 2328 & 5635 & 9575 \\
\hline & $w_{\mathrm{cr}}(\mu \mathrm{m})$ & 5 & 9 & 12 \\
\hline \multirow{2}{*}{ Ref. } & \multirow{2}{*}{ Index } & \multicolumn{3}{|c|}{ Number of FTCs } \\
\hline & & 50 & 100 & 150 \\
\hline Hasan et al. & $\Delta \mathrm{V} / \mathrm{V}_{0}(\mathrm{vol}-\%)^{*}$ & 0.09 & 0.18 & 0.24 \\
\hline 2004 & $\varepsilon\left(\times 10^{-6}\right)$ & 314 & 596 & 809 \\
\hline
\end{tabular}

* indicates the calculated results using the corresponding experimental data. 
Table 3 Parameters for mass (water and chloride) transport in different phases of concrete

\begin{tabular}{ccccc}
\hline Diffusivity & & & & \\
coefficient & Mortar & ITZ & Crack & Aggregate \\
\hline$D_{0}\left(\mathrm{~mm}^{2} / \mathrm{hr}\right)$ & 0.06 & 0.541 & 4200 & 0 \\
$D_{\mathrm{cl} 1}\left(\mathrm{~mm}^{2} / \mathrm{hr}\right)$ & 0.35 & 3.5 & 3000 & 0 \\
\hline
\end{tabular}

